\title{
Food through the child's eye: an eye-tracking study on attentional bias for food in healthy-weight children and children with obesity
}

Citation for published version (APA):

Werthmann, J., Jansen, A., Vreugdenhil, A. C. E., Nederkoorn, C., Schyns, G., \& Roefs, A. (2015). Food through the child's eye: an eye-tracking study on attentional bias for food in healthy-weight children and children with obesity. Health Psychology, 34(12), 1123-1132. https://doi.org/10.1037/hea0000225

Document status and date:

Published: 01/12/2015

DOI:

10.1037/hea0000225

Document Version:

Publisher's PDF, also known as Version of record

Document license:

Taverne

Please check the document version of this publication:

- A submitted manuscript is the version of the article upon submission and before peer-review. There can be important differences between the submitted version and the official published version of record.

People interested in the research are advised to contact the author for the final version of the publication, or visit the DOI to the publisher's website.

- The final author version and the galley proof are versions of the publication after peer review.

- The final published version features the final layout of the paper including the volume, issue and page numbers.

Link to publication

\footnotetext{
General rights rights.

- You may freely distribute the URL identifying the publication in the public portal. please follow below link for the End User Agreement:

www.umlib.nl/taverne-license

Take down policy

If you believe that this document breaches copyright please contact us at:

repository@maastrichtuniversity.nl

providing details and we will investigate your claim.
}

Copyright and moral rights for the publications made accessible in the public portal are retained by the authors and/or other copyright owners and it is a condition of accessing publications that users recognise and abide by the legal requirements associated with these

- Users may download and print one copy of any publication from the public portal for the purpose of private study or research.

- You may not further distribute the material or use it for any profit-making activity or commercial gain

If the publication is distributed under the terms of Article $25 \mathrm{fa}$ of the Dutch Copyright Act, indicated by the "Taverne" license above, 


\title{
Food Through the Child's Eye: An Eye-Tracking Study on Attentional Bias for Food in Healthy-Weight Children and Children With Obesity
}

\author{
Jessica Werthmann \\ Maastricht University and King's College London
}

Anita C. E. Vreugdenhil

Maastricht University Medical Centre

\author{
Anita Jansen \\ Maastricht University
}

\begin{abstract}
Objective: Obesity prevalence among children is high and knowledge on cognitive factors that contribute to children's reactivity to the "obesogenic" food environment could help to design effective treatment and prevention campaigns. Empirical studies in adults suggest that attention bias for food could be a risk factor for overeating. Accordingly, the current study tested if children with obesity have an elevated attention bias for food when compared to healthy-weight children. Another aim was to explore whether attention biases for food predicted weight-change after 3 and 6 months in obese children. Method: Obese children $(n=34)$ were recruited from an intervention program and tested prior to the start of this intervention. Healthy-weight children $(n=36)$ were recruited from local schools. First, attention biases for food were compared between children with obesity $(n=30)$ and matched healthy-weight children $(n=30)$. Second, regression analyses were conducted to test if food-related attention biases predicted weight changes after 3 and 6 months in children with obesity following a weight loss lifestyle intervention. Results: Results showed that obese children did not differ from healthy-weight children in their attention bias to food. Yet automatically directing attention toward food (i.e., initial orientation bias) was related to a reduced weight loss $\left(R^{2}=.14, p=.032\right)$ after 6 months in children with obesity. Discussion: High palatable food is a salient stimulus for all children, irrespective of their weight status. However, automatically directing attention to food cues might facilitate further weight gain in children with obesity.
\end{abstract}

Keywords: obesity, childhood, attention bias, weight gain, eye-tracking

Obesity is a serious problem worldwide, for both adults and children (Ogden, Carroll, Kit, \& Flegal, 2014; Wang \& Lim, 2012; World Health Organization, 2013). Childhood obesity is particularly problematic because it is not only associated with several severe comorbid psychological and physical problems (Pulgaron, 2013) but is also predictive of adult obesity and a risk factor for

This article was published Online First June 1, 2015.

Jessica Werthmann, Faculty of Psychology and Neuroscience, Maastricht University, and Institute of Psychiatry, Psychology and Neuroscience, King's College London; Anita Jansen, Faculty of Psychology and Neuroscience, Maastricht University; Anita C. E. Vreugdenhil, Department of Pediatrics, Maastricht University Medical Centre, The Netherlands; Chantal Nederkoorn, Ghislaine Schyns, and Anne Roefs, Faculty of Psychology and Neuroscience, Maastricht University.

We thank the Titus Brandsma Basisschool in Brunssum, the Basisschool Sint Theresia in Slenaken, and the Sophianum in Gulpen, The Netherlands, for their helpful cooperation with this study. We would also like to thank the Department of Pediatrics and the Pediatric polyclinic at the Maastricht University Medical Centre, The Netherlands, for their help in recruiting participants.

Correspondence concerning this article should be addressed to Jessica Werthmann, King's College London, Institute of Psychiatry, Psychology, and Neuroscience, Section of Eating Disorders, Denmark Hill 103, SE 5 8AF London, United Kingdom. E-mail: Jessica.Werthmann@kcl.ac.uk mortality (Cali \& Caprio, 2008). Given the negative consequences of childhood obesity, it is important to gain a better understanding of factors contributing to overeating and obesity in children in order to develop effective treatments and prevention strategies.

In the western "obesogenic" environment high-calorie and palatable foods are available everywhere and marketed aggressively, particularly to children (Halford, Gillespie, Brown, Pontin, \& Dovey, 2004; Harris, Bargh, \& Brownell, 2009; Kelly et al., 2010). All western children live in the same obesogenic environment, but many of them are not obese. Studying (cognitive) mechanisms, which could cause some children to be overly responsive to these food temptations, could contribute to a better understanding of individual differences in eating behavior and weight status.

Attention biases to palatable, high-calorie food could be one possible vulnerability factor that contributes to overeating (e.g., Berridge, 1996; Castellanos et al., 2009; Werthmann et al., 2011). Research on attention biases for food and its relation to body weight has mainly been conducted in adults, with mixed results (see, for a review, Werthmann, Jansen, \& Roefs, 2014).

For example, some studies suggest increased attention bias for food in participants with obesity vs. healthy-weight participants (e.g., Castellanos et al., 2009). Yet others report increased attention bias followed by avoidance to look at high calorie food in overweight vs. healthy-weight participants (e.g., Werthmann et al., 2011), or even 
increased attentional avoidance of food cues with increasing body mass index (BMI; e.g., Nummenmaa et al., 2011). Other studies report no association between food-related attentional biases and BMI (e.g., Loeber et al., 2012).

Although a number of studies on attention bias for food have been conducted in adults, only two studies so far have been conducted in children with obesity (Braet \& Crombez, 2003; Soetens \& Braet, 2007). Similar to findings on attentional bias for food in adults, these two studies provided contradictory evidence for an attention bias for food cues in children with overweight and obesity when compared to healthy-weight children. One study, using a food Stroop task (Braet \& Crombez, 2003), showed that children with obesity were slower in naming the color of a colored food word than a colored neutral word, as compared to healthy-weight children. Accordingly, the authors concluded that children with obesity found it more difficult to suppress processing the meaning of food words and might thus be more preoccupied with food, whereas healthy-weight children were not distracted by the meaning of food words (Braet \& Crombez, 2003). The other study (Soetens \& Braet, 2007) used an embedded word task comprising high-calorie food words and matched control words as a measure of attention bias for food in overweight and healthy-weight adolescents (between 12 and 18 years). The embedded word task consists of a grid of words and nonwords and requires detecting as many words as possible during a certain time interval (in this study 6 minutes). No significant differences in the number of detected food words were found between overweight and healthy-weight adolescents, indicating that the two groups did not differ in their processing of hidden food words (Soetens \& Braet, 2007).

The diversity of research findings in both adult and pediatric samples could be due to methodological differences in the assessment of attentional bias. When measuring attention bias, an important distinction can be made between an indirect and a direct assessment of attention allocation. Both studies in pediatric samples relied on indirect tasks. A recognized difficulty of assessing attention biases indirectly (e.g., by response latencies) is that only a snap-shot view of attention processes can be provided (Mogg, Bradley, Field, \& De Houwer, 2003). Indirect assessments rely on inferences on attention allocation during the critical stimulus presentation and often fail to inform us of the direction of attention or the underlying temporal attention components (e.g., Field, Munafò, \& Franken, 2009; Mogg et al., 2003). A direct measure of visual attention allocation is eyetracking, and a recent meta-analysis concluded that eye-movements are the most sensitive measure to capture visual attention biases (Field et al., 2009). The current study advances previous studies on attention bias in children by measuring food-related attentional allocation as closely as possible, using eye-tracking technology in addition to the assessment of response latencies.

By means of eye-tracking, different temporal components of attention can be identified within each trial and insight on the direction of attention is provided. This information is important for research on attention bias and eating behavior. For example, the direction of the attention process (i.e., looking toward or away from food) has been associated with subsequent increase or decrease of food intake in adults (e.g., Werthmann, Field, Roefs, Nederkoorn, \& Jansen, 2014). Moreover, information on different temporal attention components is important because they are thought to reflect automatic versus controlled attention processes (LaBerge, 2002). For example, initial attention orientation and initial gaze durations are thought to reflect more automatic processes of attentional bias. Dwell time bias (main- tained attention) on food stimuli presumably reflects more controlled and wilful attention allocation. Research suggested that these different temporal attention components might have differential associations with subsequent eating behavior and craving (Field et al., 2009; Werthmann et al., 2011). Table 1 provides an overview of attention bias components based on a direct assessment of visual attention as provided by eye-tracking.

Research on the role of attentional bias for food in relation to BMI has mainly been conducted cross-sectionally, leaving the relation of an attention bias for food and subsequent weight change unexplored. However, two recent studies suggest that increased attentional processing of unhealthy food cues predicts increase in BMI in female adolescents (Yokum, Ng, \& Stice, 2011) and a student sample (Calitri, Pothos, Tapper, Brunstrom, \& Rogers, 2010). Hence, the current study explored whether attentional biases predict weight change over time in children with obesity who were enrolled in a lifestyle intervention.

To sum up, the primary aim of the current study was to test if children with obesity have an elevated attention bias for high-calorie food when compared to matched healthy-weight children, using eyetracking technology as a dynamic and direct measure of visual attention. Another aim was to extend the cross-sectional design of previous research, and to test prospectively whether attention bias for food could predict weight change over 3 and 6 months in children with obesity following a lifestyle intervention.

We expected that children with obesity would show enhanced attentional biases toward high-calorie food images in comparison to healthy-weight children (Hypothesis 1). In addition, we hypothesized that stronger attentional biases for food would be predictive of reduced weight loss or increased weight gain at 3 and 6 months follow-up in children with obesity following a lifestyle intervention to lose weight (Hypothesis 2).

\section{Method}

\section{Participants}

Thirty-four children with obesity, who were enrolled in an outpatient pediatric obesity lifestyle intervention at the local academic hospital, and 36 healthy-weight children recruited from local schools were tested. For our first hypothesis, which involved testing a crosssection of obese and healthy children and determining whether their attention bias for food differed, we found an individual matching on age and gender in 30 obese/healthy-weight children pairs. Thus, our cross-sectional analysis is based on a subsample of all tested obese children (30 out of 34 children) and healthy-weight children (30 out of 36 children). For our second hypothesis, testing whether attention biases for food related to weight change over 3 and 6 months in obese children, we included all 34 tested obese children. However, data on three children was missing on the reassessment of height and weight after 3 months and thus this analysis was based on data of 31 obese children. At the 6-month reassessment, data on two children was missing and thus this analysis was based on data of 32 children. $^{1}$

\footnotetext{
${ }^{1}$ The cross-sectional analysis, testing Hypothesis 1, was repeated including all tested 34 obese children and 36 healthy-weight children and results remained the same. Similarly, follow-up analyses, testing Hypothesis 2, were repeated for the subsample of the 30 obese children (included to test Hypothesis 1) also yielded the same results as when including the whole subsample of obese children.
} 
All participants received the same information about the study with an information letter and an informed consent form. Recruitment procedures differed slightly per participant group. Children with obesity and their parents were approached in the pediatric obesity unit at the hospital, and were asked to participate in the current study at one of their first appointments there, prior to the start of a lifestyle intervention for weight loss. Thus, the participating children with obesity partook in the current experimental procedure prior to the start of the lifestyle intervention. The children with obesity then proceeded to follow the first 6 months of the lifestyle intervention, which was planned to continue for a longer duration. During this time, follow-up measurements of weight and height in the obese children were obtained for the current study. The children with obesity included in our study represent only a small subsample of the children included in the lifestyle intervention. Clinical effectiveness results regarding the lifestyle intervention, as well as a description of the lifestyle intervention, will be reported in due time in a separate report.

Healthy-weight children were approached in their schools. Children received information verbally by one of the experimenters and their parents received information leaflets. Healthy-weight children were informed that they were only eligible for participation if they had a healthy-weight (based on self-report) and would match in the mean age and gender range of included children with obesity. If parents and their children provided informed consent they were invited for participation.

Six schoolchildren were tested but not included in analyses, because at the end of data collection, they did not match tested obese participants in age and/or gender $(n=4)$ or because assessment of the BMI at the end of testing indicated that they were overweight $(n=2)$. So, 30 children with obesity and 30 healthyweight children who were matched individually on age and gender were included in data analyses for testing Hypothesis 1 (i.e., differences in attentional biases between children with obesity and healthy-weight children). Matching was successful, in that the groups of children with obesity and healthy-weight children did not differ on age, $t(29)=0.14, p=.89$, or gender distribution, $\chi^{2}(1,60)=0.00, p=1$, see Table 2 for characteristics. The percentage of overweight was calculated based on the BMI divided by the national (Dutch) norm BMI (Van Winckel \& Van Mil, 2001), adjusted for gender and age, $\times 100$ (for a similar classification, see, e.g., Braet \& Crombez, 2003; Nederkoorn, Coelho, Guerrieri, Houben, \& Jansen, 2012; Soetens \& Braet, 2007). According to this percentage a value of $100 \%$ indicates $0 \%$ overweight. A BMI percentage of $90-120 \%$ is regarded as a healthy BMI range for a child. A percentage of $120-140 \%$ of the ideal weight is classified as overweight, a percentage of $140-160 \%$ is classified as moderate obesity, and a percentage of $160 \%$ is regarded as serious obesity. According to this classification, nine $(30 \%)$ of the tested children with obesity were moderately obese and $21(70 \%)$ were severely obese (range: $142.28-232.56 \%$ ). All healthy-weight children had an adjusted BMI within the healthy weight range (range: 81.67-116.84\%). For mean adjusted BMI per group, see Table 2 .

Three- and 6-month follow-up data on BMI for 31 and 32 children with obesity, respectively, was available throughout the assessment in the hospital and was used to test Hypothesis 2 (i.e., whether attentional biases for food cues predict weight change over time). 
Table 2

Participants Characteristics and Mean Attentional Bias Scores Statistical Tests of Group Differences Between Healthy-Weight and Children With Obesity

\begin{tabular}{|c|c|c|c|c|c|c|c|}
\hline & \multicolumn{2}{|c|}{$\begin{array}{l}\text { Healthy-weight } \\
\text { children }(n=30)\end{array}$} & \multicolumn{2}{|c|}{$\begin{array}{l}\text { Children with obesity } \\
\qquad(n=30)\end{array}$} & \multicolumn{3}{|c|}{ Test statistic } \\
\hline & $M$ & $S D$ & $M$ & $S D$ & $t(d f)$ & $\chi^{2}(d f)$ & $p$ (two-tailed) \\
\hline Age & 11.82 & 2.99 & 11.91 & 2.93 & $t(58)=.12$ & & $p=.91$ \\
\hline Gender & \multicolumn{2}{|c|}{13 boys/17 girls } & \multicolumn{2}{|c|}{13 boys/17 girls } & & $\chi^{2}(1)=.00$ & $p=1$ \\
\hline BMI & 17.16 & 1.85 & 30.61 & 4.81 & $t(58)=14.28$ & & $p<.001$ \\
\hline Adjusted $\mathrm{BMI}^{\mathrm{a}}$ & 97.49 & 8.95 & 176.05 & 23.05 & $t(58)=17.40$ & & $p<.001$ \\
\hline School type & \multicolumn{2}{|c|}{$\begin{array}{l}15 \text { primary/15 } \\
\text { secondary }\end{array}$} & \multicolumn{2}{|c|}{$\begin{array}{c}19 \text { primary/11 } \\
\text { secondary }\end{array}$} & & $\chi^{2}(1)=1.09$ & $p=.29$ \\
\hline Initial orientation bias ${ }^{\mathrm{a}}$ & 53.51 & 9.85 & 52.90 & 7.23 & $t(58)=.27$ & & $p=.79$ \\
\hline Initial gaze duration bias ${ }^{\mathrm{b}}$ & 94.26 & 271.66 & 53.65 & 273.35 & $t(58)=.58$ & & $p=.56$ \\
\hline Dwell time bias ${ }^{\mathrm{b}}$ & 123.27 & 338.46 & -10.68 & 354.38 & $t(58)=1.50$ & & $p=.14$ \\
\hline Response latency bias ${ }^{\mathrm{b}}$ & 20.52 & 52.95 & -1.64 & 57.76 & $t(58)=1.55$ & & $p=.13$ \\
\hline
\end{tabular}

Note. $\quad$ BMI $=$ body mass index; adjusted BMI = BMI divided by the national (Dutch) norm BMI (Van Winckel \& Van Mil, 2001), adjusted for gender and age, $\times 100$. Initial orientation bias $=N$ of first fixations on high-calorie food stimuli/( $N$ of first fixations on high-calorie food stimuli $+\mathrm{N}$ of first fixations on non-food stimuli) ${ }^{*} 100$. Initial gaze duration bias = mean duration of the sum of initial fixations occurring within region of high-calorie food stimuli when initially fixated on - mean duration of the sum of initial fixations occurring within region of non-food stimuli when initially fixated on. Dwell time bias $=$ mean total dwell time on high-calorie food stimuli - mean total dwell time on non-food stimuli. Response latency bias $=$ Mean response latency in congruent trials - mean response latency in incongruent trials.

${ }^{\mathrm{a}}$ in $\% . \quad{ }^{\mathrm{b}}$ in $\mathrm{ms} .{ }^{\mathrm{c}}$ unequal variances: $d f$ were corrected; $t$ and $p$ are reported accordingly.

\section{Pictorial Visual Probe Paradigm}

Overview. Attention allocation toward high-calorie food stimuli was measured during a visual probe task with concurrent recordings of eye movements as a direct measure of attention bias, and the assessment of response latencies as an indirect index of attention bias. In the visual probe task, two images are presented simultaneously side by side followed by a probe $\left(^{*}\right)$ appearing in the location of one of the images. Children were instructed to indicate the location of the probe as quickly as possible by pressing a corresponding key on a standard computer keyboard. Children first completed a brief practice round to get familiarized with the visual probe task.

Timing trials. Each trial started with a central fixation cross, which remained on the screen for $100 \mathrm{~ms}$. Subsequently, the target image pair was presented for 3,000 ms. Then the probe $\left(^{*}\right)$ was presented until the participant responded by pressing the appropriate key on a button box.
Trial types. A brief practice round with 10 trials was included prior to the actual task. The actual visual probe paradigm included 80 trials in total: 64 critical trials and 16 filler trials. These trials were divided into two blocks of each 40 trials. Critical trials consisted of 16 stimulus pairs, each presented four times. Filler trials consisted of four stimulus pairs, each presented four times. The position of the probe was equally distributed per stimulus type and displayed on the left and right side of the screen in equal measure. The order of trials was uniquely randomized for each participant.

Stimuli. In critical trials, the image pair consisted of a picture of a high-calorie food item and a picture of an animal (e.g., crisps and little ducklings; see Figure 1 for illustration). Filler trials consisted of picture pairs depicting two neutral nonfood photographs (e.g., shoes and furniture). All image pairs were matched as closely as possible with regard to color, complexity and brightness, and size of the depicted object. A pilot test was conducted to match
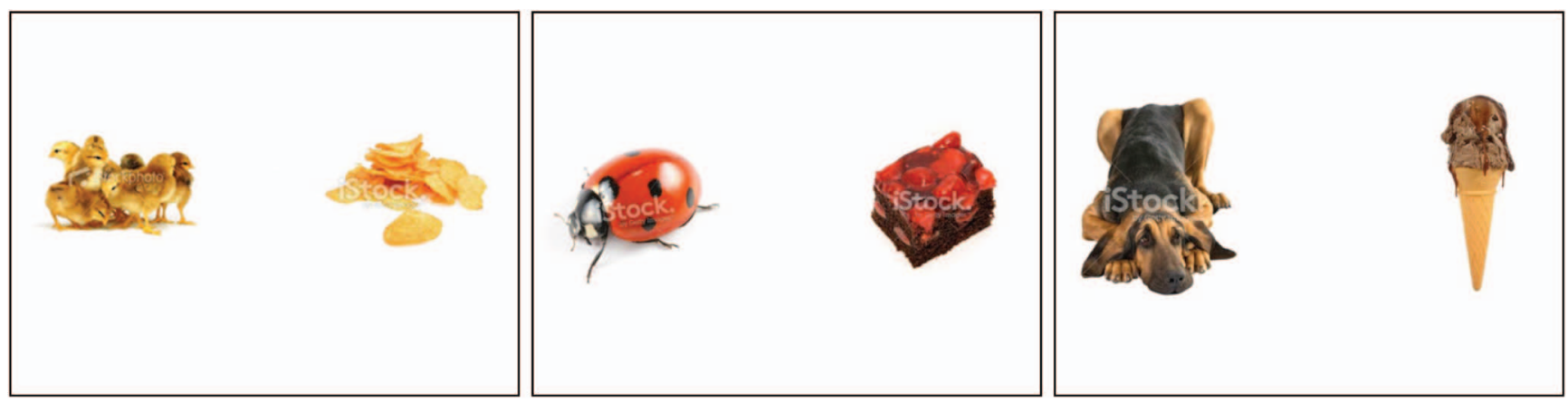

Figure 1. Examples of critical picture pairs depicted in the visual probe task. Pictures are depicted here with watermark due to copyright. However, in our study, pictures were displayed without watermark. See the online article for the color version of this figure. 
food and animal stimuli on attractiveness. For critical picture pairs, pictures of animals were matched with pictures of palatable, highcalorie food on visual features and pictures of furniture and shoes were matched on visible feature to create neutral filler picture pairs. In the pilot, 65 schoolchildren rated a pool of 48 matched critical picture pairs and 18 matched neutral filler picture pairs on the valence and attractiveness of each of the depicted stimuli on a 5 -point Likert scale, with higher scores indicating more attractiveness. Based on these ratings, the 20 picture critical pairs in which the food stimulus and the animal stimulus were rated most attractive and at the same time most similar in terms of attractiveness were used in this study $\left(M_{\text {ratings animals }}=3.89, S D=\right.$

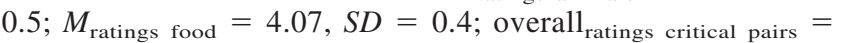
$3.88, S D=0.3$ ). For filler trials, 10 of the most neutrally and similarly rated neutral filler pairs were included (overall $\left.M_{\text {ratings filler pairs }}=2.99, S D=0.3\right)$. Each picture was presented equally often on the left and on the right of the screen. For practice trials, pictures pairs consisted of photographs of neutral nonfood items, which were different from the photographs used for filler trials. See Figure 1 for examples of critical picture pairs.

Eye movement measurements. Eye movements were recorded by a desktop mounted EyeLink 1000 system (SR Research Ltd., Mississauga, Ontario, Canada). A 9-point calibration with subsequent validation procedure was conducted prior to the visual probe paradigm. To assess attention allocation processes, participants' gaze fixations were studied. Gaze fixations were defined as any period that is not a blink or saccade and lasts at least $100 \mathrm{~ms}$ ("EyeLink Data Viewer User's Manual," 2011). Eye movements that occurred before the presentation of an image pair were excluded, because these movements could represent anticipatory fixations.

For analysis purposes, the computer screen was divided into three areas of interest: the midsection, which indicated the location of the fixation cross, and the left and right sections, representing the locations of the picture stimuli. Only eye movements in critical trials directed either to the left or the right section of the screen were extracted for further analyses. Eye movements in filler trials and gaze fixations in the mid area were excluded from further analyses. Eye movements were extracted using Data Viewer (SR Research Ltd., Mississauga, Ontario, Canada).

Attention bias scores. Three attention bias scores were derived from the eye movement data: initial orientation bias scores, initial gaze duration bias scores and gaze dwell time bias scores, see also Table 1.

An initial orientation bias reflects an early attentional process, and is calculated based on the number of first fixations that are directed to a high-calorie food picture as a proportion of all trials on which a first fixation is made to either picture (Castellanos et al., 2009; Werthmann et al., 2013). A bias score of 50\% indicates no bias for food, a bias score greater than $50 \%$ represents a higher proportion of first fixations directed to high-calorie food stimuli, whereas a bias score lower than $50 \%$ indicates a higher proportion of first fixations directed to nonfood stimuli.

The initial gaze duration bias is seen as a measure for early attention maintenance (e.g., Bradley, Mogg, Wright, \& Field, 2003). This bias is calculated based on the sum of multiple fixations occurring within the region of the initially fixated picture before gaze is shifted away. This means that the first initial fixation may be followed by a second or third fixation within the same picture. The sum of these initial fixations together indicates initial gaze duration before the person looked away from the picture. Initial gaze durations per image category (high-calorie food or nonfood) were averaged over the relevant trials per participant. Bias scores for the initial gaze duration were computed by subtracting the mean duration of initial fixation directed to nonfood images from the mean duration of initial fixation directed to high-calorie food images. Thus, a positive score is indicative of longer initial attention maintenance on high-calorie food stimuli, whereas a negative score is indicative of the reverse: longer initial maintenance on nonfood stimuli.

Gaze dwell time is informative regarding the maintenance of attention on critical stimuli (e.g., Mogg, Field, \& Bradley, 2005). Overall dwell time per image category (high-calorie food vs. nonfood) was calculated for each critical trial, and then averaged per image category over all trials, resulting in an average total dwell time per image category. For the gaze dwell time bias score, the mean dwell time on nonfood images was subtracted from the mean dwell time on high-calorie food images. Thus, a positive score indicates that attention was maintained longer on highcalorie food items than on nonfood items, whereas a negative score indicates the reverse: longer maintained attention on nonfood items.

Manual response latencies to probes. The logic of the visual probe task presumes that participants are faster to respond to probes appearing in the location of the stimulus that they attended and are slower to respond to probes appearing in the location of the stimulus that they did not attend (MacLeod, Mathews, \& Tata, 1986). Participant's manual response latencies when indicating the location of the probe were used to calculate response latency bias scores. Based on a stimulus duration of $3,000 \mathrm{~ms}$, the response latency bias indirectly reflects a maintained attention process. For analysis, response latencies from incorrect trials were excluded ( $1.9 \%$ of all trials). Response latencies were excluded from further analyses if they were faster than $200 \mathrm{~ms}$, slower than 2,000 ms, and if they deviated more than $3 \mathrm{SDs}$ from each participant's mean (2.1\% of all trials; e.g., Castellanos et al., 2009; Mogg, Bradley, Hyare, \& Lee, 1998). Based on this calculation, $4 \%$ of data was discarded. Response latency bias scores were then calculated by subtracting the mean response latency on congruent trials (i.e., when the probe replaced a high-calorie food image) from the mean response latency on incongruent trials (that is, when the probe appeared in the same location as the preceding nonfood image). A positive bias score indicates an attention bias toward high-calorie food, whereas a negative bias score indicates an attention bias away from high-calorie food.

\section{Procedure}

All children were tested individually in a dimly lit room between 9 a.m. and 12 p.m. Healthy-weight children were tested at their respective schools and children with obesity were tested in a laboratory room at the Faculty of Psychology \& Neuroscience, Maastricht University, as part of a general baseline assessment of their physical and psychological condition at the hospital. After a brief validation procedure to adjust eyetracking parameters, children first completed the 10 practice 
trials and subsequently continued with the first half of the visual probe task. The visual probe task was split in two blocks to give children the possibility to take a brief rest of about 1 or 2 minutes between blocks. After the short break, children completed the second half of the visual probe task. Then children or their parents provided information on age and school type. Finally, weight and height were measured without shoes and in light clothing to calculate the BMI and the adjusted BMI. Weight was measured using a digital scale and height was measured with a tape measure. Weight and height for children with obesity was subsequently assessed at their 3-month and their 6-month follow-up appointment at the hospital. All children received compensation with the value of $€ 7.50$ for their participation in the experiment. The current study received ethical approval from the ethics committee of the Faculty of Psychology \& Neuroscience, Maastricht University and from the medical-ethical committee at the local academic hospital.

\section{Data Analysis}

To test if healthy-weight children differ in their attention bias for food from children with obesity (Hypothesis 1), an independent $t$ test with group (healthy-weight vs. obese) as independent variable was conducted for the four measures of attention biases (initial orientation, initial gaze duration, dwell time, response latencies). To test further if observed attention bias scores were significantly stronger for food images, several one-sample $t$ tests were conducted for the whole group. To test if all children initially looked more often at the food image than at the nonfood image, a one-sample $t$ test for initial orientation bias (tested against 50, indicating no bias) was conducted. To test if children remained with their attention longer on food versus nonfood stimuli, one-sample $t$ tests against 0 (indicating no bias on the attention-maintenance based attention measures) were conducted for initial duration bias, for dwell time bias and for the response latency bias.

To test Hypothesis 2, we explored if attention biases for food predicted BMI change at 3 months and at 6 months in children with obesity who were enrolled in the lifestyle intervention. First, BMI change for 3 and 6 months was computed for all children with obesity. For BMI change after 3 months, the adjusted BMI \% at time of testing was subtracted from the adjusted BMI \% at 3 months. Similarly for BMI change after 6 months, the adjusted BMI \% at testing was subtracted from the adjusted BMI $\%$ at 6 months. A positive score represents an increase in adjusted BMI \%, thus weight gain over time adjusted for gender and age, whereas a negative score represents a decrease in adjusted BMI \%, thus weight loss adjusted for gender and age. Follow-up data at 3 and 6 months were missing for two children who stopped coming to their regular appointments at the hospital, and for one child who missed the appointment at 3 months. Follow-up data on the remaining sample of 32 children with obesity was used for analyses at 6 months and for 31 children with obesity at 3 months. BMI change at 3 and BMI change at 6 months (based on \% overweight, adjusted for gender and age, according to the national norms) was entered as dependent variable in the two regression analyses, respectively. All four attentional bias measures (initial orientation, initial gaze duration, dwell time and response latencies) were centered before being entered as predictors into the respective regression model. As previous research does not give an indication which attention bias measure might be the best predictor for BMI change over time, an exploratory approach was chosen by selecting the backward method as analytic strategy to determine which predictor has a significant effect on BMI change.

\section{Results}

\section{Participant Characteristics}

Participating children were on average about 12 years old $\left(M_{\text {age }}=11.86, S D=2.93\right.$, age range $=6.45-16.82$ years $)$ More girls $(n=34)$ than boys $(n=26)$ participated. Although matching children in age was successful, more obese children were still in the primary school at the time of testing in comparison to healthy-weight children, even though this difference was not significant, see Table 2 for all participants' characteristics.

\section{Do Attentional Biases Differ Between Healthy-Weight Children and Children With Obesity?}

Healthy-weight children and children with obesity were compared on attentional bias measures (initial direction, initial gaze duration, dwell time, response latencies). Results showed that attention for food did not differ on any of the attentional bias measures between children with obesity and healthy-weight children, all $t \mathrm{~s}<1.50$, all $p \mathrm{~s}>.14$, see Table 2 for exact statistics. Further, one sample $t$ tests indicated that all children directed their first gaze more often toward food cues than nonfood cues $(M=53.21, S D=8.58), t(59)=2.90, p=.005$. Moreover, all children also maintained their first gaze longer on food cues than on nonfood cues $(M=73.95, S D=270.96)$, $t(59)=2.11, p=.039$. No significant results for dwell time bias $(M=56.30, S D=350.14), t(59)=1.24, p=.22$, and response latency bias $(M=9.44, S D=56.06), t(59)=1.30$, $p=.20$, were obtained, indicating that attention was not maintained longer on food images than nonfood images in later attention processes in the whole sample.

\section{Do Attentional Biases Predict Change in BMI After 3 and 6 Months?}

Mean adjusted BMI change was $-1.58 \%(S D=8.88)$ at 3 months and $-2.40 \%(S D=10.82)$ at 6 months. Inspection of a scatterplot suggested that one participant had an outlying decrease in adjusted BMI scores after 3 months $(-28.68 \%$ change in adjusted BMI; i.e., 3.05 SDs below the mean adjusted BMI change) and after 6 months ( $-38.90 \%$ change in adjusted BMI; i.e., 3.30 SDs above the mean adjusted BMI change), and therefore these outlying BMI changes were recoded to the nearest BMI change score in the obese group $(-19.58 \%$, i.e., 2.04 SDs below the mean adjusted BMI change, and $-19.21 \%$; i.e., 1.55 SDs below the mean adjusted BMI change, respectively; see Wilcox, 
2011) prior to the regression analysis. ${ }^{2}$ Results of the regression analysis testing if attention bias measures predicted BMI change at 3 months indicated that none of the attentional bias measures were significantly related to change in adjusted BMI after 3 months in children with obesity enrolled in a lifestyle intervention, all $\beta<$ .16 , all $p s>.45$.

Results of the regression analysis testing if any of the attention bias measures was related to BMI change at 6 months showed that initial orientation bias significantly predicted changes in BMI after 6 months, $\beta=0.38, t(30)=2.24, p=.032$, and explained $14 \%$ of variance in BMI change after 6 months, $R^{2}=.14, F(30)=5.03$, $p=.032$, see Figure 2 .

This finding suggests that initially directing attention more often toward food than nonfood stimuli was related to a reduced weight loss or even weight gain after 6 months in children with obesity enrolled in a lifestyle intervention.

\section{Discussion}

Attention bias for food might contribute to increased food intake and therefore constitute a cognitive mechanism contributing to the development and/or maintenance of obesity. The primary aim of this study was to test whether children with obesity differ in their attention bias for food from healthy-weight children. A second aim was to test if attention bias for food predicts subsequent weight change in children with obesity who were, by then, following a weight loss lifestyle intervention. To test these hypotheses, attention bias for food was measured in healthy-weight children and in children with obesity using a visual probe task depicting food and nonfood stimuli with concurrent assessment of eye-movements and measurement of response latencies.

Contrary to our first hypothesis, our results provide no empirical evidence for differences in attentional biases for food between children with obesity and healthy-weight children. Instead, our results suggest that all children have a tendency to orientate toward palatable high-calorie food cues (i.e., initial orientation bias) and

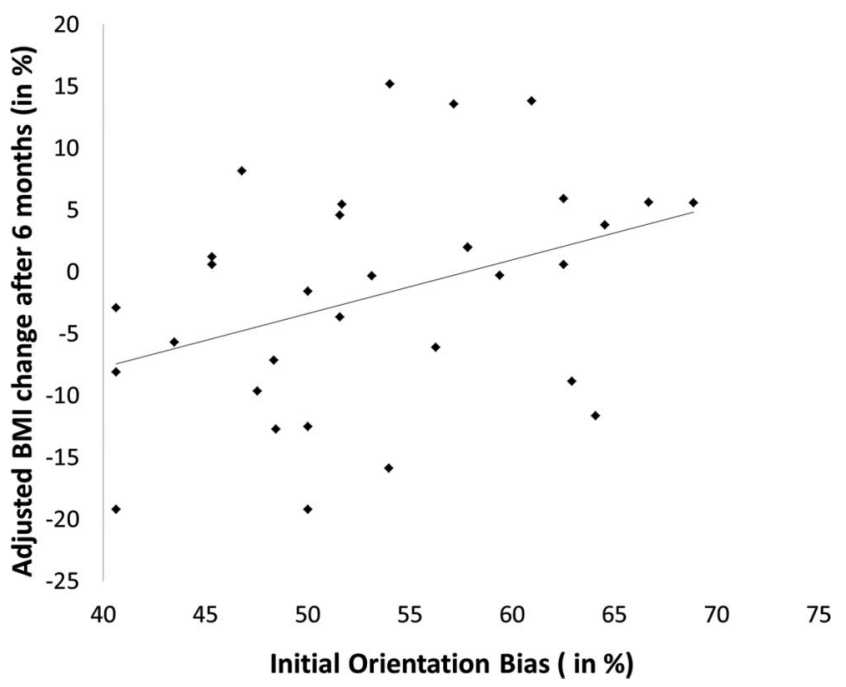

Figure 2. Correlation of adjusted body mass index (BMI) change after 6 months (in \%) in children with obesity $(n=32)$ and initial orientation bias scores (in \%, a percentage above 50 indicates a bias toward food). initially maintain their first gaze longer on food cues than on nonfood cues (i.e., initial gaze duration bias). These findings suggest that palatable high-calorie food cues are highly salient stimuli for all children, irrespective of their weight status. Considering that food items were more powerful in capturing children's initial attention even when paired with equally liked animal pictures, our results therefore highlight the prominence of food cues in the "obesogenic" environment for children.

Although the observation that all children, not only children with obesity, have an attention bias for food cues concurs with similar findings in adults suggesting that all adults have an attentional bias for food, irrespective of their weight (e.g., Nijs, Franken, \& Muris, 2008; Werthmann, Roefs, Nederkoorn, \& Jansen, 2013; Werthmann, Roefs, Nederkoorn, Mogg, et al., 2013), it contradicts studies that demonstrated differences in attention bias for food in obese versus healthy-weight adults and children (Braet \& Crombez, 2003; Castellanos et al., 2009). One possible explanation for this diversity of results is related to the choice of paradigm and the choice of relevant stimuli. Different paradigms tap into different attention processes: Indirect measures of attention bias, as applied in previous studies with pediatric samples, might reflect processes other than direct measurements of visual attention, as applied in the current study. For example, the assessment of response latencies as a measure for attention bias has been debated and researchers have argued that the indirect assessment of attention bias via response latencies may not be reliable (Ataya et al., 2012; Field \& Christiansen, 2012; Kappenman, Farrens, Luck, \& Proudfit, 2014).

Thus, a particular strength of the current study was that the direct assessment of attention allocation (by means of eyetracking) complemented indirect measurements of attention processes. Eye-tracking provides a more detailed and accurate account of visual information processing, thereby overcoming the disadvantage of indirect attention indices, which reflect only a snap-shot view of attention allocation (based on the stimulus duration) and cannot inform on attention processes during the stimuli presentation itself (see, e.g., Mogg et al., 2003). In contrast, eye-tracking based attention bias scores reflect attentional processing during the stimuli presentation and can provide information on different temporal components of attention and on attentional approach or avoidance. Hence, previous studies might have come to different results because they relied on indirect assessment of attention and therefore tapped into a different mechanism than visual processing of food cues.

Moreover, the stimulus selection might also affect attentional processes. Previous research that measured food-related attention often contrasted high-calorie food items with a relatively neutral stimulus category, such as office supplies or musical instruments. In this respect, the current study highlights the power of an attentional bias for food cues by demonstrating that even in contrast to a highly liked contrast category (i.e., equally liked animal pictures), food cues were more potent in grabbing attention. Thus, the current study extends previous research on food-cue related attentional biases by showing that even in contrast to compara-

\footnotetext{
${ }^{2}$ Results remained the same when we included this participant with the original BMI change scores in our data analysis.
} 
tively attractive other objects, food cues are more capable of grabbing early attention.

Another explanation for the diverse results could be that all children have an innate attention bias for food, yet attention bias for food might wane in healthy-weight children during the course of their development, whereas attention bias for food might remain heightened, in contrast to other stimuli in the environment, in children with obesity. However, this argument is purely speculative and future research should further investigate how attention biases for food change over time in healthy-weight and obese children.

In this respect, the results concerning our second hypothesis might be important in showing that a bias in initial orientation toward food positively predicted weight gain after 6 months in children with obesity who were enrolled in a weight loss intervention. This finding supports the hypothesized role of attention in the etiology and maintenance of obesity: directing attention toward food might be a vulnerability factor for overconsumption, and thus subsequent weight gain. However, based on our results it is not clear if this process is specific for children with obesity following a lifestyle intervention or could also be observed in healthy-weight children or children with obesity who are not enrolled in a lifestyle intervention. Yet, in general, our findings are in line with results obtained in adolescents and young adults. For example, a neuroimaging study yielded that activity in brain regions associated with attention, during the presentation of food cues, was positively related to BMI and weight gain over 12 months in female adolescents (Yokum et al., 2011). Similarly, another study demonstrated that Stroop interference for unhealthy food words predicted weight gain in a mainly healthy-weight student sample, whereas Stroop interference for healthy food words negatively predicted weight change (Calitri et al., 2010). A clinical implication of this finding is that attentional retraining might be a useful adjunct to treatments that focus on weight-loss for obese children. Just recently a novel study supported this notion by showing that an attentional training was related to eating in the absence of hunger in obese children (Boutelle, Kuckertz, Carlson, \& Amir, 2014).

With regard to the role of specific temporal attention components, it is interesting to note that the early attention component was associated with reduced weight loss or even weight gain in the current study. In contrast, previous research on substance use and food intake suggested that a later attentional component, namely maintained attention, was associated with subsequent consumption (e.g., Field et al., 2009; Werthmann, Roefs, Nederkoorn, \& Jansen, 2013). A possible explanation for this divergence could be that a later attention component reflects a rather conscious decision about eating, and thereby predicts immediate consumption. Early attention, on the other hand, might reflect less conscious motivational vulnerability to overconsumption, and thereby predicts weight change over time. Yet, this conclusion is rather speculative and further research is needed to determine the impact of different temporal attention components on eating behavior and weight change over time.

Our results should be viewed under the limitations of our study: Even though a pilot test indicated that children rated animal pictures as similarly well liked as food pictures, we did not ask children in the current study to rate the attractiveness of animal and food pictures. Accordingly, it is possible that the participating children preferred food pictures over animal pictures and this could have affected the observed results. Moreover, even though all children were tested in the morning, after breakfast, we did not formally check if all children indeed consumed breakfast and did not assess subjective hunger states. Considering that research (e.g., Loeber, Grosshans, Herpertz, Kiefer, \& Herpertz, 2013) suggests that hunger influences an attention bias for food, the current results should be viewed under this limitation.

Differences in the testing environment for obese children (university/hospital) and healthy-weight children (schools) might have induced different mind-sets: Obese children might have been more focused on a healthy mind-set whereas healthy-weight children might have been less focused on a healthy mind-set. Previous research demonstrated that such a mind-set can influence implicit measures of food evaluation (Roefs et al., 2006). Thus, even though speculative, it is possible that our results underestimate the attentional bias in children with obesity, because obese children's attention bias for high-calorie food might have been attenuated by a testing environment that is associated with "health."

In addition, as mentioned previously, our results on the relation of an attentional bias and BMI change over time apply only for children with obesity participating in a lifestyle intervention to lose weight and might be underpowered. Future studies should therefore extend our results and test the impact of an attentional bias on weight change within a larger sample of both healthy-weight children and children with obesity who are not enrolled in a lifestyle intervention.

Despite these limitations, the present study has several strengths. A highly innovative aspect of the current study is that the relation of visual attention bias for food and BMI differences was measured within a pediatric sample and the relation of an attentional bias for food and weight change was explored in obese children following a lifestyle intervention to lose weight. A major methodological strength is the combination of an indirect and a direct assessment for biased attention. Another novelty of this study was the use of valence-matched nonfood stimuli (i.e., pictures of cute animals) as a contrast to the food stimuli, which is also a methodological strength because these picture pairs were pilot-tested with regard to the attractiveness of depicted food/ animals.

Taken together, the current findings might partly explain how the current food environment influences children's eating behavior: food cues grab the attention of all children, even when other attractive alternatives are available. Our results moreover suggest that biased attention for high-calorie foods increases the chance of future weight gain in children with obesity. Our results stress the "toxic" impact of an obesogenic food environment on children's perception and on obesity in children.

\section{References}

Ataya, A. F., Adams, S., Mullings, E., Cooper, R. M., Attwood, A. S., \& Munafò, M. R. (2012). Internal reliability of measures of substancerelated cognitive bias. Drug and Alcohol Dependence, 121(1-2):148151. http://dx.doi.org/10.1016/j.drugalcdep.2011.08.023

Berridge, K. C. (1996). Food reward: Brain substrates of wanting and liking. Neuroscience and Biobehavioral Reviews, 20, 1-25. http://dx.doi .org/10.1016/0149-7634(95)00033-B

Boutelle, K. N., Kuckertz, J. M., Carlson, J., \& Amir, N. (2014). A pilot study evaluating a one-session attention modification training to de- 
crease overeating in obese children. Appetite, 76, 180-185. http://dx.doi .org/10.1016/j.appet.2014.01.075

Bradley, B. P., Mogg, K., Wright, T., \& Field, M. (2003). Attentional bias in drug dependence: Vigilance for cigarette-related cues in smokers. Psychology of Addictive Behaviors, 17, 66-72. http://dx.doi.org/ 10.1037/0893-164X.17.1.66

Braet, C., \& Crombez, G. (2003). Cognitive interference due to food cues in childhood obesity. Journal of Clinical Child and Adolescent Psychology, 32, 32-39. http://dx.doi.org/10.1207/S15374424JCCP3201_04

Cali, A. M., \& Caprio, S. (2008). Obesity in children and adolescents. The Journal of Clinical Endocrinology and Metabolism, 93(11, Suppl 1), S31-S36. http://dx.doi.org/10.1210/jc.2008-1363

Calitri, R., Pothos, E. M., Tapper, K., Brunstrom, J. M., \& Rogers, P. J. (2010). Cognitive biases to healthy and unhealthy food words predict change in BMI. Obesity, 18, 2282-2287. http://dx.doi.org/10.1038/oby .2010 .78

Castellanos, E. H., Charboneau, E., Dietrich, M. S., Park, S., Bradley, B. P., Mogg, K., \& Cowan, R. L. (2009). Obese adults have visual attention bias for food cue images: Evidence for altered reward system function. International Journal of Obesity, 33, 1063-1073. http://dx.doi .org/10.1038/ijo.2009.138

EyeLink Data Viewer User's Manual (Document Version 1.11.1). (2011). EyeLink Data Viewer. SR Research, Mississauga, Ontario, Canada.

Field, M., \& Christiansen, P. (2012). Commentary on Ataya et al. (2012), "Internal reliability of measures of substance-related cognitive bias." Drug and Alcohol Dependence, 124, 189-190. http://dx.doi.org/ 10.1016/j.drugalcdep.2012.02.009

Field, M., Munafò, M. R., \& Franken, I. H. A. (2009). A meta-analytic investigation of the relationship between attentional bias and subjective craving in substance abuse. Psychological Bulletin, 135, 589-607. http://dx.doi.org/10.1037/a0015843

Halford, J. C., Gillespie, J., Brown, V., Pontin, E. E., \& Dovey, T. M. (2004). Effect of television advertisements for foods on food consumption in children. Appetite, 42, 221-225. http://dx.doi.org/10.1016/j.appet .2003 .11 .006

Harris, J. L., Bargh, J. A., \& Brownell, K. D. (2009). Priming effects of television food advertising on eating behavior. Health Psychology, 28, 404-413. http://dx.doi.org/10.1037/a0014399

Kappenman, E. S., Farrens, J. L., Luck, S. J., \& Proudfit, G. H. (2014). Behavioral and ERP measures of attentional bias to threat in the dotprobe task: Poor reliability and lack of correlation with anxiety. Frontiers in Psychology, 5, 1368. http://dx.doi.org/10.3389/fpsyg.2014 .01368

Kelly, B., Halford, J. C., Boyland, E. J., Chapman, K., Bautista-Castaño, I., Berg, C., . . Summerbell, C. (2010). Television food advertising to children: A global perspective. American Journal of Public Health, 100, 1730-1736. http://dx.doi.org/10.2105/AJPH.2009.179267

LaBerge, D. (2002). Attentional control: Brief and prolonged. Psychological Research, 66, 220-233. http://dx.doi.org/10.1007/s00426-0020097-2

Loeber, S., Grosshans, M., Herpertz, S., Kiefer, F., \& Herpertz, S. C. (2013). Hunger modulates behavioral disinhibition and attention allocation to food-associated cues in normal-weight controls. Appetite, 71, 32-39. http://dx.doi.org/10.1016/j.appet.2013.07.008

Loeber, S., Grosshans, M., Korucuoglu, O., Vollmert, C., Vollstädt-Klein, S., Schneider, S., . . Kiefer, F. (2012). Impairment of inhibitory control in response to food-associated cues and attentional bias of obese participants and normal-weight controls. International Journal of Obesity, 36, 1334-1339. http://dx.doi.org/10.1038/ijo.2011.184

MacLeod, C., Mathews, A., \& Tata, P. (1986). Attentional bias in emotional disorders. Journal of Abnormal Psychology, 95, 15-20. http://dx .doi.org/10.1037/0021-843X.95.1.15

Mogg, K., Bradley, B. P., Field, M., \& De Houwer, J. (2003). Eye movements to smoking-related pictures in smokers: Relationship be- tween attentional biases and implicit and explicit measures of stimulus valence. Addiction, 98, 825-836. http://dx.doi.org/10.1046/j.1360-0443 2003.00392.x

Mogg, K., Bradley, B. P., Hyare, H., \& Lee, S. (1998). Selective attention to food-related stimuli in hunger: Are attentional biases specific to emotional and psychopathological states, or are they also found in normal drive states? Behaviour Research and Therapy, 36, 227-237. http://dx.doi.org/10.1016/S0005-7967(97)00062-4

Mogg, K., Field, M., \& Bradley, B. P. (2005). Attentional and approach biases for smoking cues in smokers: An investigation of competing theoretical views of addiction. Psychopharmacology, 180, 333-341. http://dx.doi.org/10.1007/s00213-005-2158-x

Nederkoorn, C., Coelho, J. S., Guerrieri, R., Houben, K., \& Jansen, A (2012). Specificity of the failure to inhibit responses in overweight children. Appetite, 59, 409-413. http://dx.doi.org/10.1016/j.appet.2012 .05 .028

Nijs, I. M. T., Franken, I. H., \& Muris, P. (2008). Food cue-elicited brain potentials in obese and healthy-weight individuals. Eating Behaviors, 9, 462-470. http://dx.doi.org/10.1016/j.eatbeh.2008.07.009

Nummenmaa, L., Hietanen, J. K., Calvo, M. G., \& Hyönä, J. (2011). Food catches the eye but not for everyone: A BMI-contingent attentional bias in rapid detection of nutriments. PLOS ONE, 6(5), e19215. http://dx.doi .org/10.1371/journal.pone.0019215

Ogden, C. L., Carroll, M. D., Kit, B. K., \& Flegal, K. M. (2014). Prevalence of childhood and adult obesity in the United States, 2011-2012. Journal of the American Medical Association, 311, 806-814. http://dx .doi.org/10.1001/jama.2014.732

Pulgaron, E. R. (2013). Childhood obesity: A review of increased risk for physical and psychological comorbidities. Clinical Therapeutics, 35, 14

Roefs, A., Quaedackers, L., Werrij, M. Q., Wolters, G., Havermans, R., Nederkoorn, C., . . Jansen, A. (2006). The environment influences whether high-fat foods are associated with palatable or with unhealthy. Behaviour Research and Therapy, 44, 715-736. http://dx.doi.org/ 10.1016/j.brat.2005.05.007

Soetens, B., \& Braet, C. (2007). Information processing of food cues in overweight and normal weight adolescents. British Journal of Health Psychology, 12, 285-304. http://dx.doi.org/10.1348/135910706X107604

Van Winckel, M., \& Van Mil, E. (2001). Wanneer is dik te dik? In C. Braet \& M. Van Winckel (Eds.), Behandelingsstrategieen Bij Kinderen Met Overgewicht (pp. 11-26). Houten, the Netherlands: Bohn Stafleu Van Loghum.

Wang, Y., \& Lim, H. (2012). The global childhood obesity epidemic and the association between socio-economic status and childhood obesity. International Review of Psychiatry, 24, 176-188. http://dx.doi.org/ 10.3109/09540261.2012.688195

Werthmann, J., Field, M., Roefs, A., Nederkoorn, C., \& Jansen, A. (2014) Attention bias for chocolate increases chocolate consumption-An attention bias modification study. Journal of Behavior Therapy and Experimental Psychiatry, 45, 136-143. http://dx.doi.org/10.1016/j.jbtep 2013.09.009

Werthmann, J., Jansen, A., \& Roefs, A. (2014). Worry or craving? A selective review of evidence for food-related attention biases in obese individuals, eating-disorder patients, restrained eaters and healthy samples. The Proceedings of the Nutrition Society, 14, 1-16. http://dx.doi org/10.1017/S0029665114001451

Werthmann, J., Roefs, A., Nederkoorn, C., \& Jansen, A. (2013). Desire lies in the eyes: Attention bias for chocolate is related to craving and self-endorsed eating permission. Appetite, 70, 81-89. http://dx.doi.org/ 10.1016/j.appet.2013.06.087

Werthmann, J., Roefs, A., Nederkoorn, C., Mogg, K., Bradley, B. P., \& Jansen, A. (2011). Can(not) take my eyes off it: Attention bias for food in overweight participants. Health Psychology, 30, 561-569. http://dx .doi.org/10.1037/a0024291 
Werthmann, J., Roefs, A., Nederkoorn, C., Mogg, K., Bradley, B. P., \& Jansen, A. (2013). Attention bias for food is independent of restraint in healthy weight individuals-an eye tracking study. Eating Behaviors, 14, 397-400. http://dx.doi.org/10.1016/j.eatbeh.2013.06.005

Wilcox, R. R. (2011). Fundamentals of modern statistical methods: Substantially improving power and accuracy. New York, NY: Springer. http://dx.doi.org/10.1080/10615806.2011.581278

World Health Organization. (2013). Obesity and overweight. Fact Sheet 311. Retrieved from http://amro.who.int/common/Display.asp?Lang= $\mathrm{E} \& \mathrm{RecID}=10203$
Yokum, S., Ng, J., \& Stice, E. (2011). Attentional bias to food images associated with elevated weight and future weight gain: An fMRI study. Obesity, 19, 1775-1783. http://dx.doi.org/10.1038/oby.2011.168

Received November 28, 2013

Revision received February 9, 2015

Accepted February 16, 2015

\section{Members of Underrepresented Groups: Reviewers for Journal Manuscripts Wanted}

If you are interested in reviewing manuscripts for APA journals, the APA Publications and Communications Board would like to invite your participation. Manuscript reviewers are vital to the publications process. As a reviewer, you would gain valuable experience in publishing. The P\&C Board is particularly interested in encouraging members of underrepresented groups to participate more in this process.

If you are interested in reviewing manuscripts, please write APA Journals at Reviewers@apa.org. Please note the following important points:

- To be selected as a reviewer, you must have published articles in peer-reviewed journals. The experience of publishing provides a reviewer with the basis for preparing a thorough, objective review.

- To be selected, it is critical to be a regular reader of the five to six empirical journals that are most central to the area or journal for which you would like to review. Current knowledge of recently published research provides a reviewer with the knowledge base to evaluate a new submission within the context of existing research.

- To select the appropriate reviewers for each manuscript, the editor needs detailed information. Please include with your letter your vita. In the letter, please identify which APA journal(s) you are interested in, and describe your area of expertise. Be as specific as possible. For example, "social psychology" is not sufficient-you would need to specify "social cognition" or "attitude change" as well.

- Reviewing a manuscript takes time (1-4 hours per manuscript reviewed). If you are selected to review a manuscript, be prepared to invest the necessary time to evaluate the manuscript thoroughly.

APA now has an online video course that provides guidance in reviewing manuscripts. To learn more about the course and to access the video, visit http://www.apa.org/pubs/authors/reviewmanuscript-ce-video.aspx. 